\title{
Special section of BPMDS'2012: artefacts and processes for business process modeling and management
}

\author{
Selmin Nurcan • Rainer Schmidt
}

Published online: 3 June 2014

(C) Springer-Verlag Berlin Heidelberg 2014

The BPMDS series has produced 11 workshops from 1998 to 2010. Nine of these workshops were held in conjunction with CAiSE conferences. From 2011, BPMDS has become a two-day working conference attached to CAiSE (Conference on Advanced Information Systems Engineering). The topics addressed by the BPMDS series are focused on IT support for business processes. This is one of the keystones of Information Systems theory. The goals, format and history of BPMDS can be found on the web site http://www.bpmds. org/.

According to Seligman et al. [1], an information systems engineering method has four pillars: a way of thinking, a way of modeling, a way of working and a way of supporting.

The framework presented in [2] was inspired from this work and aims to evaluate the capacity of business process engineering methods to design flexible business process models. According to this framework

(i) the way of thinking verbalizes the assumptions and viewpoints of the method on the kinds of problem domains, solutions and modelers;

(ii) the way of modeling provides information on the modeling concepts, on their properties and on their relationships; gives a formalism and notation to express business process models;

(iii) the way of working structures the way in which business process models are designed; defines the possible tasks to be performed as part of the design and development

S. Nurcan $(\bowtie)$

University Paris 1 Panthéon Sorbonne, Paris, France

e-mail: nurcan@univ-paris1.fr

R. Schmidt

Munich University of Applied Sciences, Munich, Germany

e-mail: Rainer.Schmidt@hm.edu process; provides heuristics on how these tasks should be performed;

(iv) the way of supporting refers to the tools that support the design and development of business process models and offers a repository to store and to exploit them.

We observe in the literature and also in BPMDS working conferences series that research developing way of workings and methodological guidelines for designing appropriate and valuable business process models is spreading more and more. This special section presents five of them.

\section{Scope}

This special section follows the 13th edition of the BPMDS (Business Process Modeling, Development and Support) series, organized in conjunction with CAISE' 12, which was held in Gdansk, Poland, June 2012. BPMDS'2012 received 48 submissions from 26 countries, and 17 papers were selected and published in Springer LNBIP 113 volume.

The special section is targeted at both researchers and practitioners in the information systems (in the broad sense) community with a focus on business process development and business application software development. The papers in this special section reflect this focus; they are extensively modified and blind reviewed versions of five research papers that were initially presented at the BPMDS'2012 working conference.

\section{Selected papers for this special section}

The first paper by J. Pinggera, P. Soffer, D. Fahland, M. Weidlich, S. Zugal, B. Weber, H. A. Reijers and J. Mendling, 
'Styles in Business Process Modeling: an Exploration and a Model', reports that a business process model has to meet certain syntactic, semantic and pragmatic quality requirements to be of value. As a matter of fact, such quality aspects were often investigated by centering on the properties of the resulting model itself. More recently, the process of model creation was considered as a factor that influences the resulting model's quality. The work presented by Pinggera et al. contributes to this category of research and presents an explorative analysis of the process of process modeling. It identifies distinct modeling styles and factors that are supposed to influence which particular modeling style is followed.

The second paper by S. Zugal, P. Soffer, C. Haisjackl, J. Pinggera, M. Reichert and B. Weber, 'Investigating Expressiveness and Understandability of Hierarchy in Declarative Business Process Models', draws our attention on the fact that, in business process management, sub-processes have been recognized as an important factor influencing model understandability and there are no guidelines on their use yet. For declarative process models, which have recently gained attention due to their flexibility, the proper usage of modularization has not been investigated and it remains unclear whether and when hierarchy has an influence on the understandability of the process model. In this work, authors elaborate first the semantics of hierarchy in declarative process models and highlight that hierarchy is not just a question of structure but also enhances expressiveness. The paper studies also which influence can be expected for hierarchy in declarative process models.

The third paper by M. Kunze, M. Weidlich and M. Weske, 'Querying Process Models by Behavior Inclusion', presents an approach to querying process models that takes a process example as input and discovers all models that allow replaying the behavior of the query. Business processes are vital to managing organizations as they sustain a company's competitiveness. These organizations maintain collections of hundreds or thousands of process models for streamlining working procedures and facilitating process implementation. The management of large process model collections requires effective searching capabilities. Authors introduce a notion for behavioral inclusion between query and candidate process models and a measure for ranking matching models.

The fourth paper by J. B. dos Santos França, J. M. Netto, J. do E. S. Carvalho, F. M. Santoro, F. A. Baião, M. Pimentel, 'KIPO: The Knowledge-Intensive Process Ontology', presents an ontology which encompasses a clear and semantically rich definition of Knowledge-Intensive Processes. The authors argue that the latters manipulate a high degree of knowledge that is critical to the business, and this knowledge is frequently lost. The proposed ontology includes concepts from several perspectives that are crucial for a complete understanding and representation of Knowledge- Intensive Processes, namely Business Process perspective, the Business Rules perspective, the DecisionMaking Rationale perspective and the Collaboration perspective. The ontology is well-founded on the Unified Foundational Ontology.

The fifth paper by I. Bider and E. Perjons 'Design Science in Action: Developing a Modeling Technique for Eliciting Requirements on Business Process Management (BPM) Tools', addresses the need for finding practical methods for selecting appropriate BPM tools. Authors argue that the shift to cloud computing in the BPM area means increased availability of inexpensive BPM tools, delivered as services that are ready for deployment. They also remind that the suitability of a particular paradigm for creating computerized support depends upon the business process in question. Some business processes can be streamlined and optimized, making workflow-based tools a perfect match for building BPS systems. For others, a social software tool, such as a wiki, can be an appropriate choice. As a matter of fact, selecting a BPM tool to build a BPS system for a particular process requires an understanding of the nature of the process at hand. Authors propose a high-level Model to capture enough details of the business process to produce a list of requirements on a business process modeling tool or a business process support system.

Acknowledgments We wish to thank the referees from the BPMDS'2012 Program Committee for their timely and accurate reviews during the two-round and blind review process, namely Eric Andonoff, Renata Araujo, Pere Botella, Maya Daneva, Johny Ghattas, Claude Godart, Renata Guizzardi, Marta Indulska, Paul Johannesson, Marite Kirikova, Christian Koot, Agnes Koschmider, Andreas Oberweis, Oscar Pastor, Iris Reinhartz-Berger and Shazia Sadiq. We would like to thank the Editors-in-Chief of the Journal of Software and Systems Modeling for agreeing to publish this special section on Business Processes and Business Process Modeling. We particularly would like to thank Martin Schindler for his excellent support in helping us put this special section together. Our gratitude also goes to the authors who made this special section possible by submitting their work and revising it according to the reviewers' comments.

\section{References}

1. Seligmann, P.S., Wijers, G.M., Sol, H.G.: Analyzing the structure of IS methodologies, an alternative approach. In: Proceedings of the First Dutch Conference on Information Systems, Amersfoort, the Netherlands (1989)

2. Daoudi, F., Nurcan, S.: A benchmarking framework for methods to design flexible business processes. Special issue of the Software Process: Improvement and Practice Journal on "Business Process Management, Development and Support" 12(1), 51-63, JanuaryFebruary (2007) 


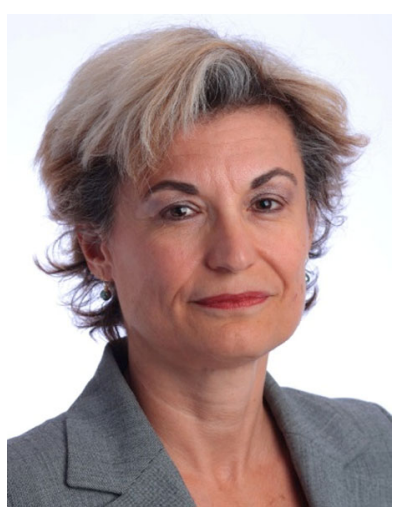

Selmin Nurcan is an Associate Professor at the University Paris 1 Panthéon-Sorbonne and a senior researcher at the 'Centre de Recherche en Informatique' (CRI). She has a Ph.D. and an engineering degree in Computer Science. Her research interests include enterprise computing, business process management, change modeling, business/IS alignment, IS governance, process (re)engineering and IS engineering and CSCW. Selmin Nurcan is co-organizer of the BPMDS series at CAISE since 2007, co-founder and co-organizer of the BPMS2 workshop series at BPM since 2008, and the SoEA4EE workshop series at EDOC since 2009. She is serving on the editorial board of several international journals such us International Journal of Information System Modeling and Design, International Journal of Information Systems in the Service Sector, Requirements Engineering Journal, and she is the associate editor of the e-journal on Advances in Enterprise Systems.

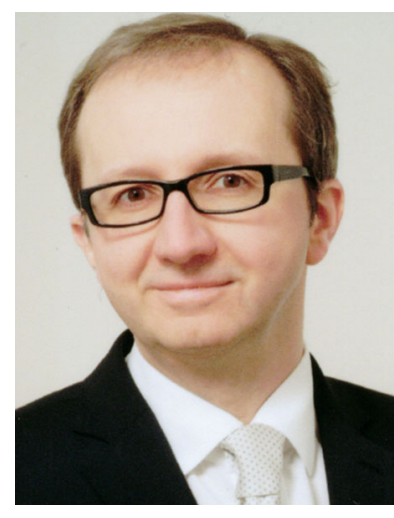

Rainer Schmidt is a professor for business information systems at Munich University of Applied Sciences. He has a Ph.D. and an engineering degree in Computer Science. His current research areas include service science, enterprise computing, business process management, social software, business/IS alignment and the integration of these themes. He has industrial experience as management consultant and researcher. Rainer Schmidt is co-organizer of the BPMDS working conference at CAISE, the BPMS2 workshop series at BPM since 2008, the SoEA4EE workshop series in EDOC since 2009 and member of the program committee of several workshops and conferences. Rainer Schmidt is serving on the editorial boards of International Journal of Information Systems in the Service Sector and International Journal on Advances in Internet Technology. Rainer Schmidt applies his research in a number of projects and cooperations with industry. 